\title{
EFFECT OF FIBRE PRE-TREATMENT AND PROCESSING ON THE WATER ABSORPTION AND MOISTURE PROPERTIES OF THE NIGERIAN SHEEP FIBRES
}

\author{
${ }^{1}$ E.S. Nwadiokwu, ${ }^{2}$ O.K. Sunmonu, ${ }^{3}$ A.S. Lawal, ${ }^{4}$ B.M Dauda \\ ${ }^{1}$ Chemical, Fibre and Environmental Technology Department, Federal Institute of \\ Industrial Research, Oshodi (FIIRO), \\ ${ }^{2,3,4}$ Department of Polymer and Textile Engineering, Faculty of Engineering, Ahmadu \\ Bello University, Zaria. \\ esnwadiokwu@gmail.com.
}

\begin{abstract}
The effect of fibre pre-treatment and processing on the water absorption and moisture properties of the Nigerian sheep fibres has been studied. The sheared fibres were pretreated by soaking, washing, rinsing and drying in order to remove the unwanted impurities and inherent constituents present in the fibres. They were further processed by separating and carding to evaluate the changes that occur in their rate of water absorption at each stage. It can be observed that the fibres at the pre-treated stage absorbs more water and has higher moisture content because of the increased pore size due to its overlapping scales which reduces when separated and carded. Therefore, this research shows that the water absorption and moisture retention ability of the sheep fibres can be affected by different stages of pre-treatment, separation and carding.
\end{abstract}

Key words: Pre-treated, water absorption, separated, carded, sheep fibres. 


\subsection{INTRODUCTION}

Hair fibres are obtained from sheep and certain other animals, including mohair from goats, angora from rabbits, and other types of wool from camelids (Braaten, 2005;Cottle, 1991; Popescu and Wortmann,2010; Sawbridge and Ford, 1987).

The term hair fibres is usually restricted to describing the fibrous protein derived from the specialized skin cells called follicles in sheep.

They readily absorb water and retain moisture, in fact, it can absorb almost one-third of its own weight in water more than any other fabrics. It is generally a creamy white color, although some breeds of sheep produce natural colors, such as black, brown, silver, and random mixes (Cottle, 1991).

Hair fibre is a luxury fibre with exceptional warmth, resilience, elasticity, fire-retardancy, quick dryability, and antistatic properties (Hassan and Leighs, 2017).

These fibres contain both inherent and acquired impurities such as dried sweat (suint), grease, blood, soil matters, dust, dirt, straw, manure and vegetable matters (Garner, 1997; Glaser, 1996). Therefore pre-treatment, separation and carding are necessary to remove these impurities and enhance water absorption and moisture retention (Banerjee et al, 2009).

\subsection{MATERIALS AND METHODS}

\subsection{MATERIALS}

Sheep fibres from a local abattoir in Lagos, Nigeria.

Hand gloves

Nose mask

Laboratory glass wares

Mixing bowls and buckets

Detergent

Razor Blade

Weighing balance

Oven

Improvised carder

Moisture analyzer (m/s-70) 


\subsection{METHODS}

\subsubsection{The Sheep Fibres}

The raw material for this research is the hair of the sheep obtained from a local abattoir in Lagos, Nigeria.

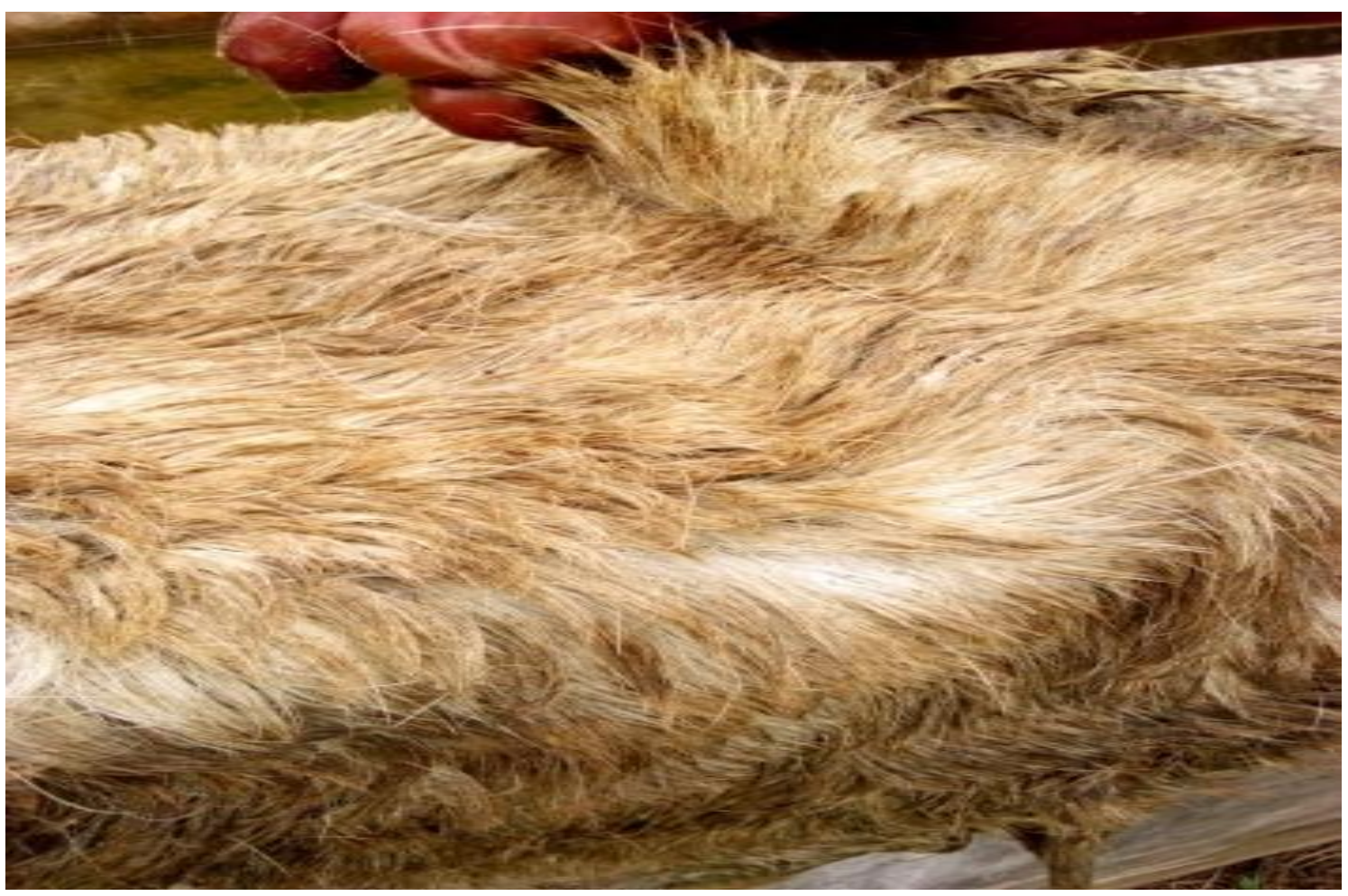

Plate 1: Raw Fibres of the Sheep Directly From the Abattoir 
Journal DOI: www.doi.org/10.46654/ij.24889849

Vol. 7, Issue 4 (April, 2021) | www.ijaar.org

Article DOI: www.doi.org/10.46654/ij.24889849.e7411

\subsubsection{Extraction of the Hair Fibres (Shearing)}

The hairs of the sheep were expertly scrapped off from their skin using a very sharp razor blade (shearing) (Dalton, et al., 2011).

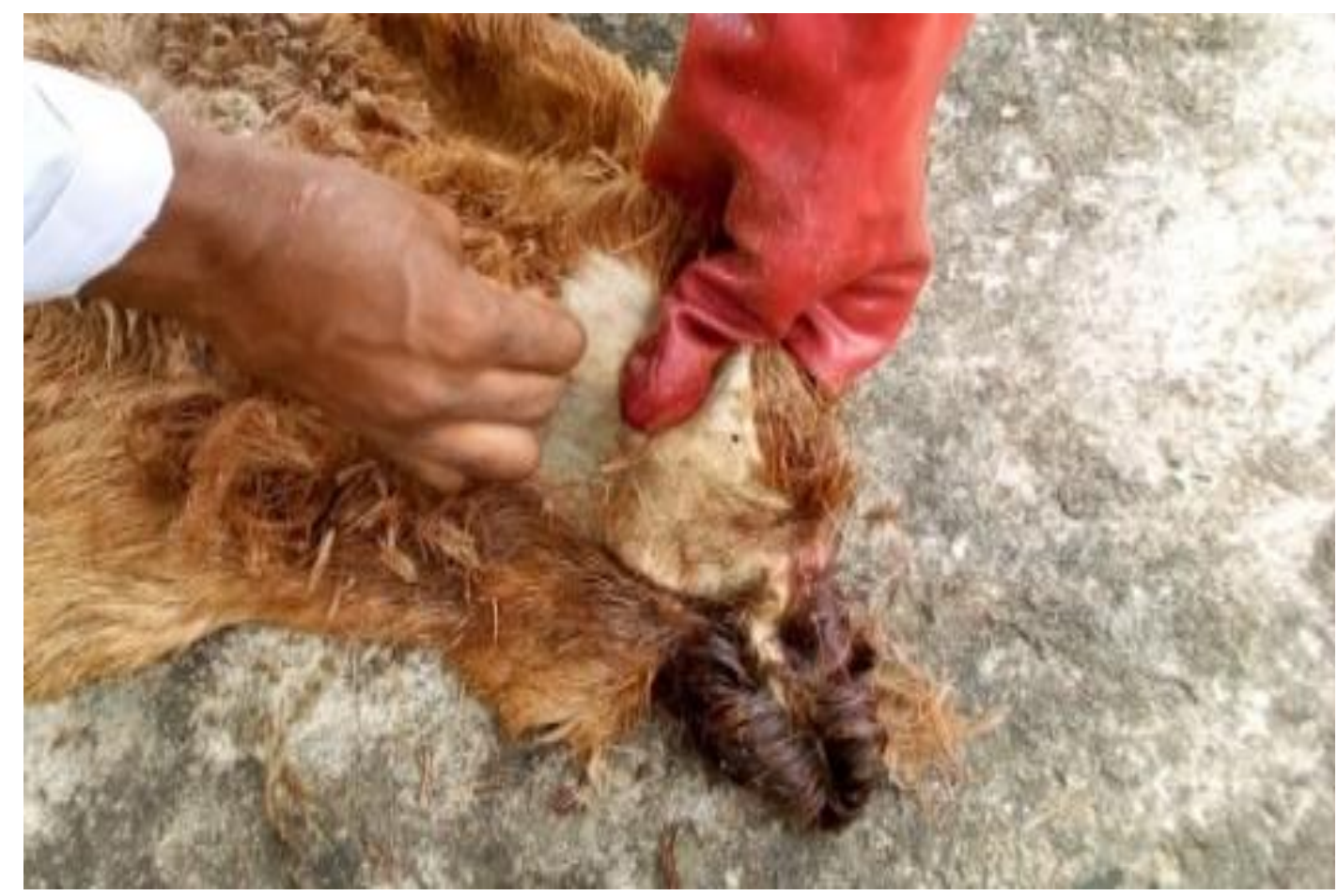


Journal DOI: www.doi.org/10.46654/ij.24889849

Article DOI: www.doi.org/10.46654/ij.24889849.e7411

\section{Plate 2: Fibre Shearing Operation}

\subsection{Pre-Treatment of the Fibres}

\subsubsection{Soaking}

The fibres were soaked in a bowl of water only for 24 hours to cause the constituents and impurities to float out.

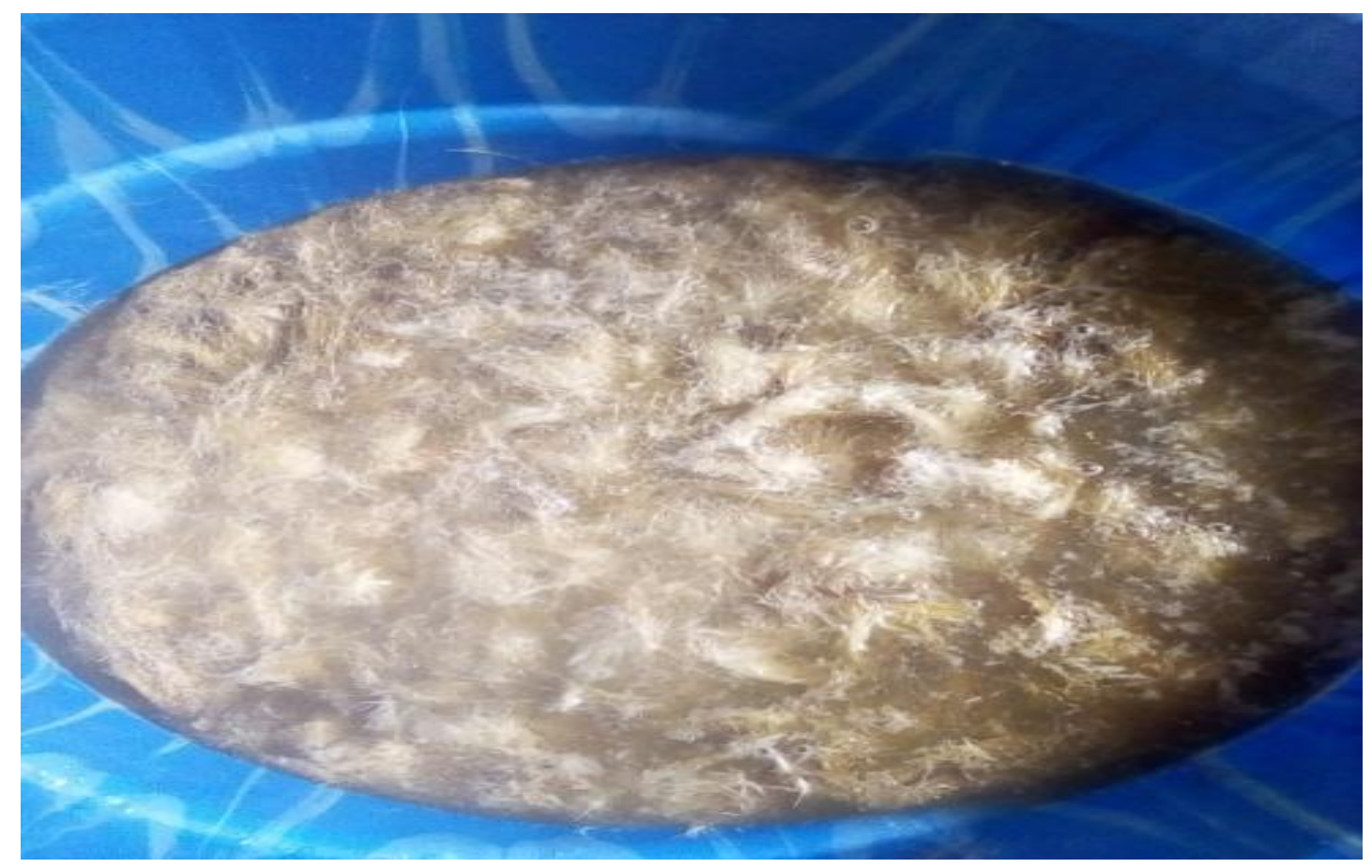

Plate 3: Soaked Sheep Fibres 


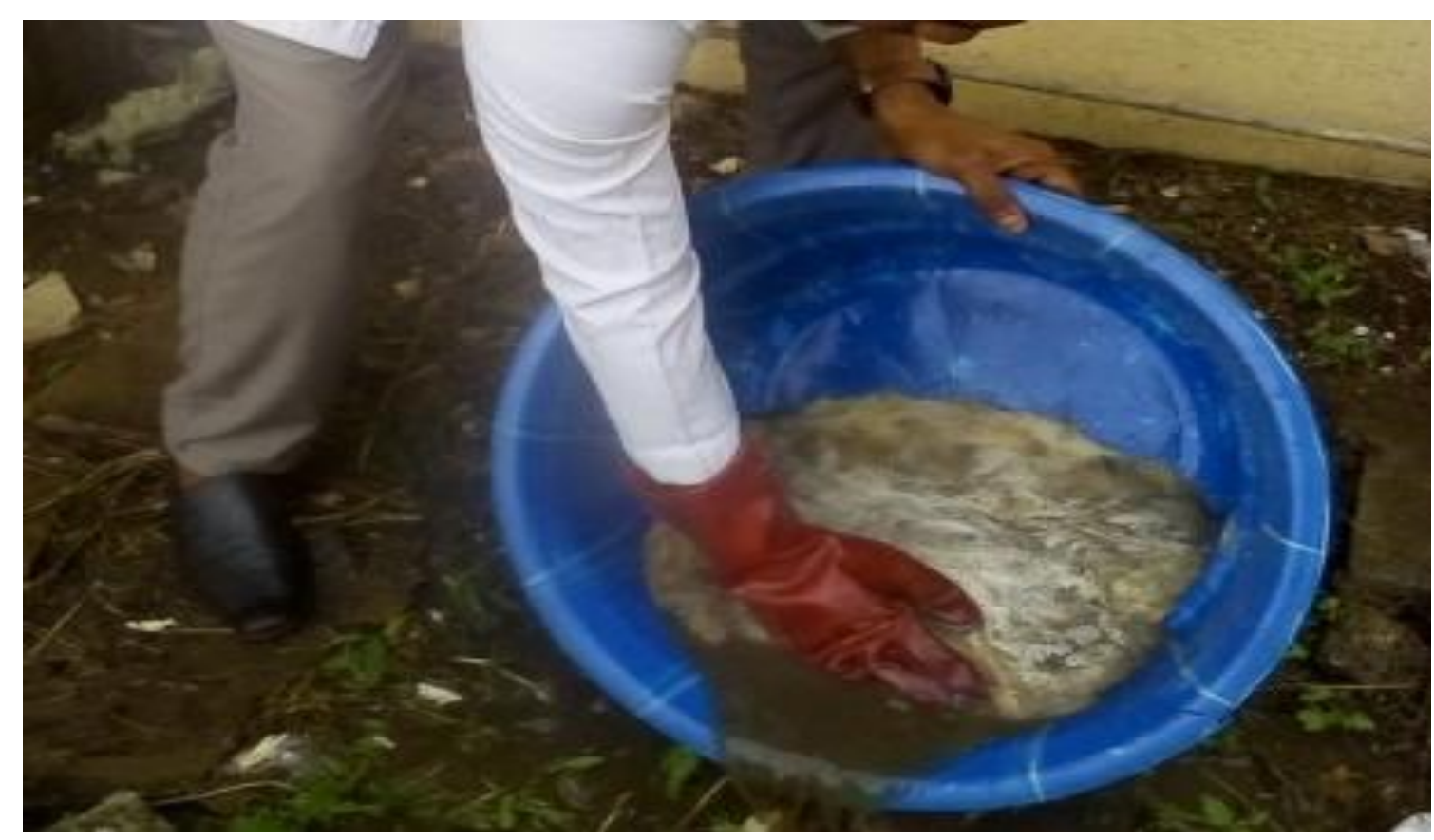

Plate 4: Rinsing the Soaked Sheep Fibres

\subsubsection{Washing, Rinsing and Drying:}

The fibres were thoroughly washed with detergent in warm water and rinsed to further remove the inherent and acquired impurities. It was then finally dried in an oven at $105^{\circ} \mathrm{C}$ for $24 \mathrm{hrs}$.

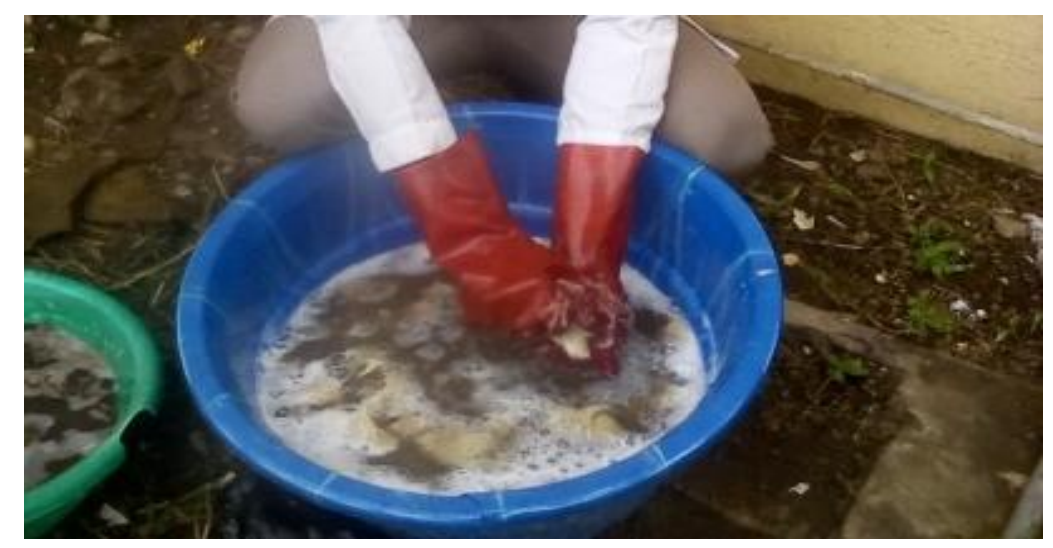

Plate 5: Washing the soaked sheep fibres 


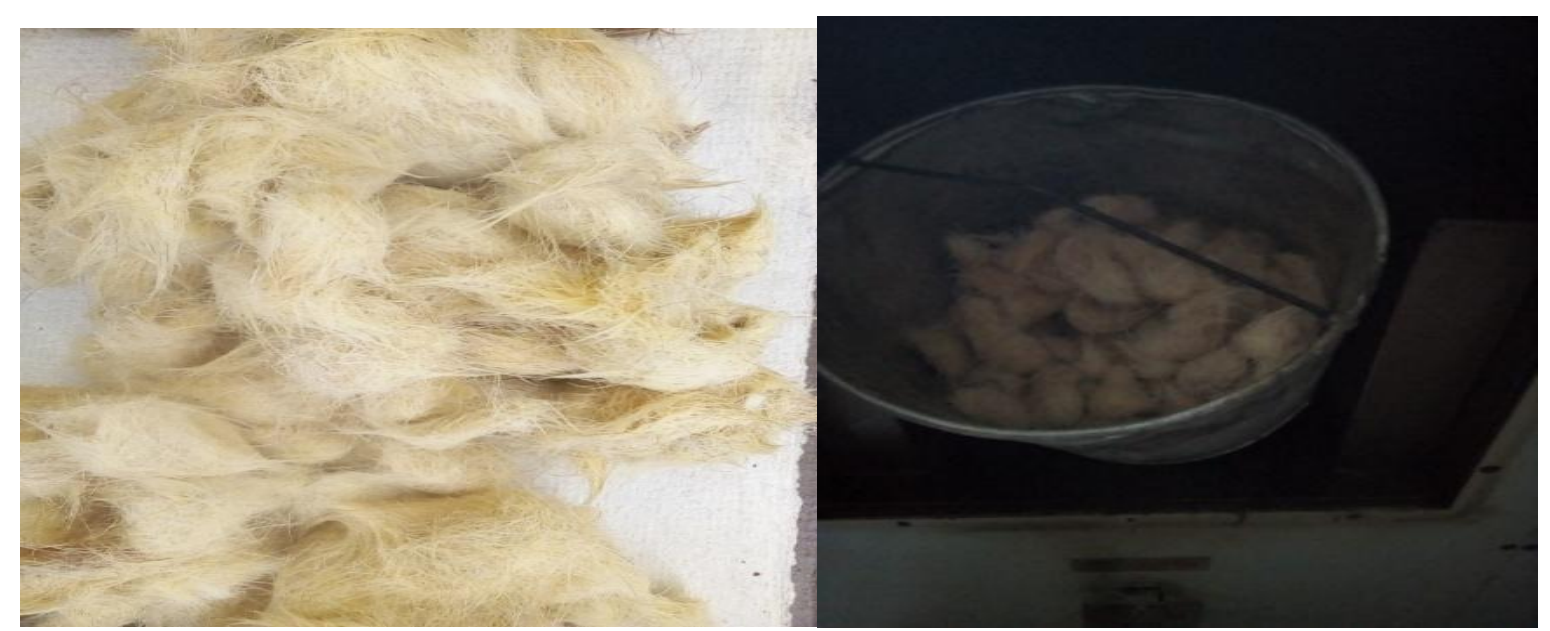

Plate 6: Washed, rinsed and dried sheep fibres. 


\subsection{Fibre Processing}

\subsubsection{Fibre Separation}

The cleaned fibres were separated using hand separating method to disentangle and singularize the mass of clustered fibres for easy carding (Moncrieff, 1953).

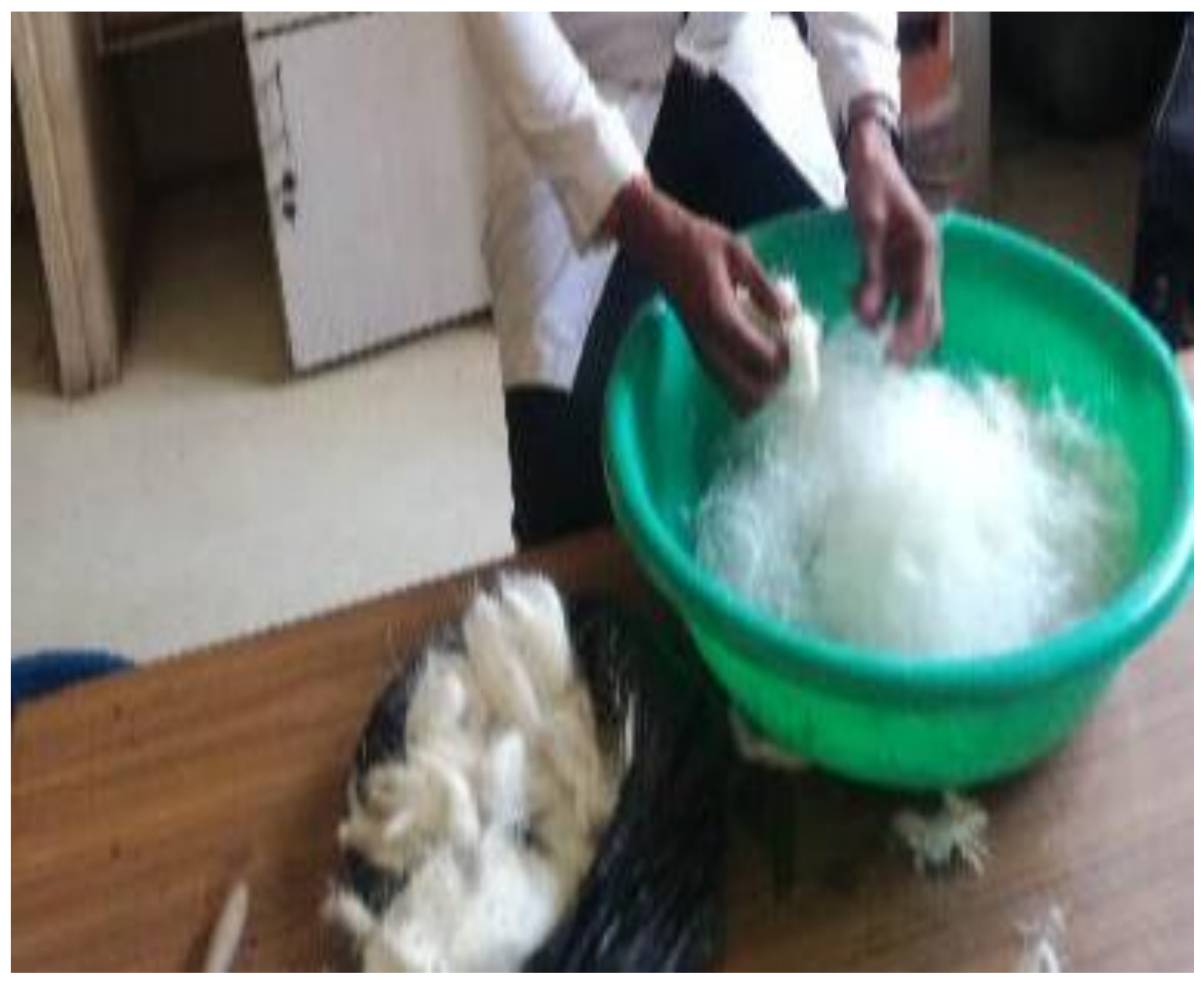

Plate 7: Fibre separation 
The separated fibres were carded using hand improvised carder resulting to an evenly smooth thin web of fibres ready for felting.

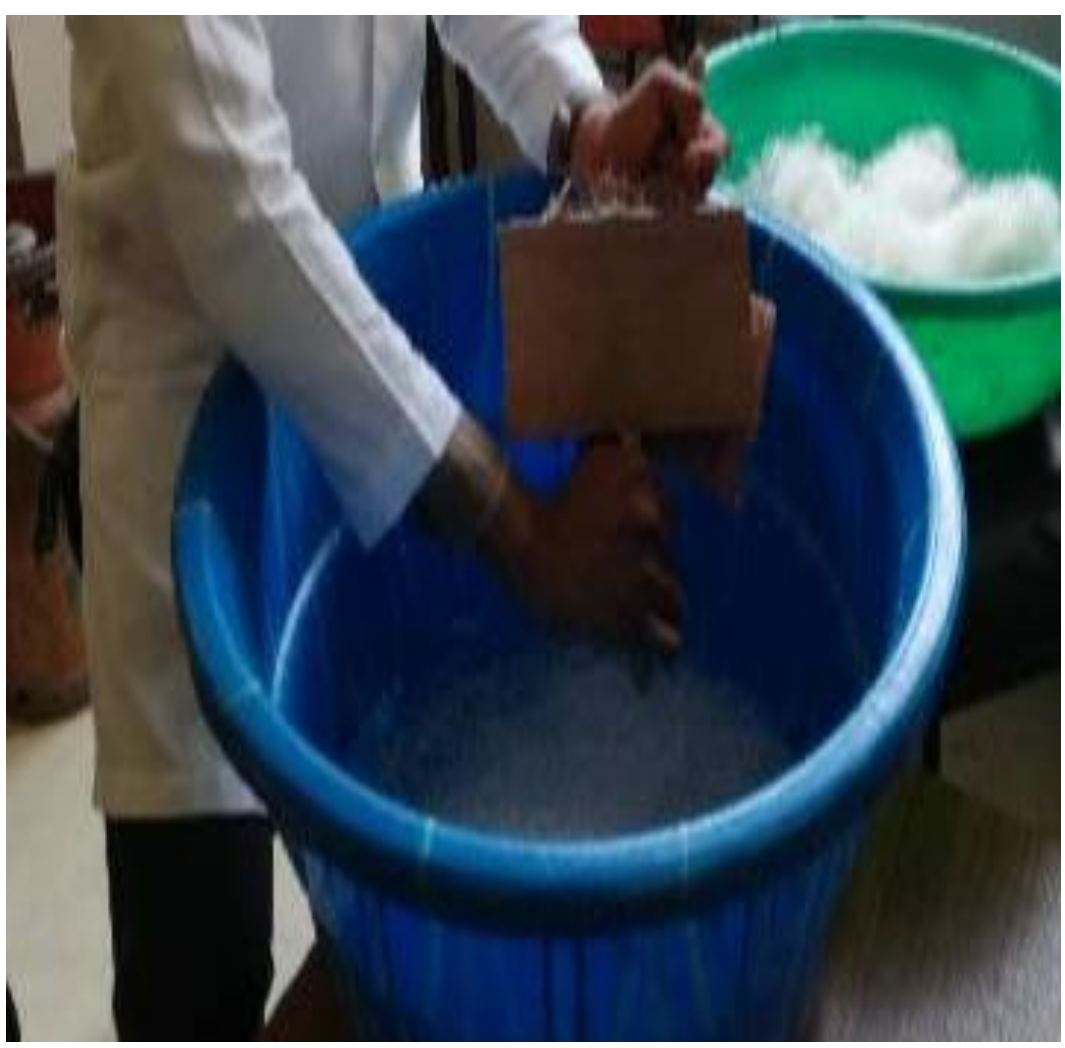

Plate 8: Fibre carding

\subsection{Moisture Content}

$2 \mathrm{~g}$ each of the pre-treated, separated and carded fibre samples of the sheep, goat and sheep/goat blend were weighted into a tray of moisture analyzer $(\mathrm{m} / \mathrm{s}-70)$. It was closed and monitored, to determine the amount of moisture present in the sample. The \% moisture content was recorded automatically by the machine. The test was carried out in triplicate and average result was taken.

\subsection{Water Absorbency Capacity}

$2 \mathrm{~g}$ each of the fibre samples of the pre-treated, separated and carded fibres were submerged in distilled water at room temperature for 24 hours. Then removed and drained for 2 3minutes.

The percentage water absorbed is calculated from the formula below.

Water absorbed $\%=\mathrm{Y}-\mathrm{X} / \mathrm{X} \times 100 / 1$ were $\mathrm{X}=$ initial weight of the fibre $\mathrm{Y}=$ final weight of the fibre. 


\subsection{RESULTS AND DISCUSSION}

\subsection{Results of Fibre Pre-treatment}

\subsubsection{Result from the Extraction (Shearing) of the Sheep Fibres}

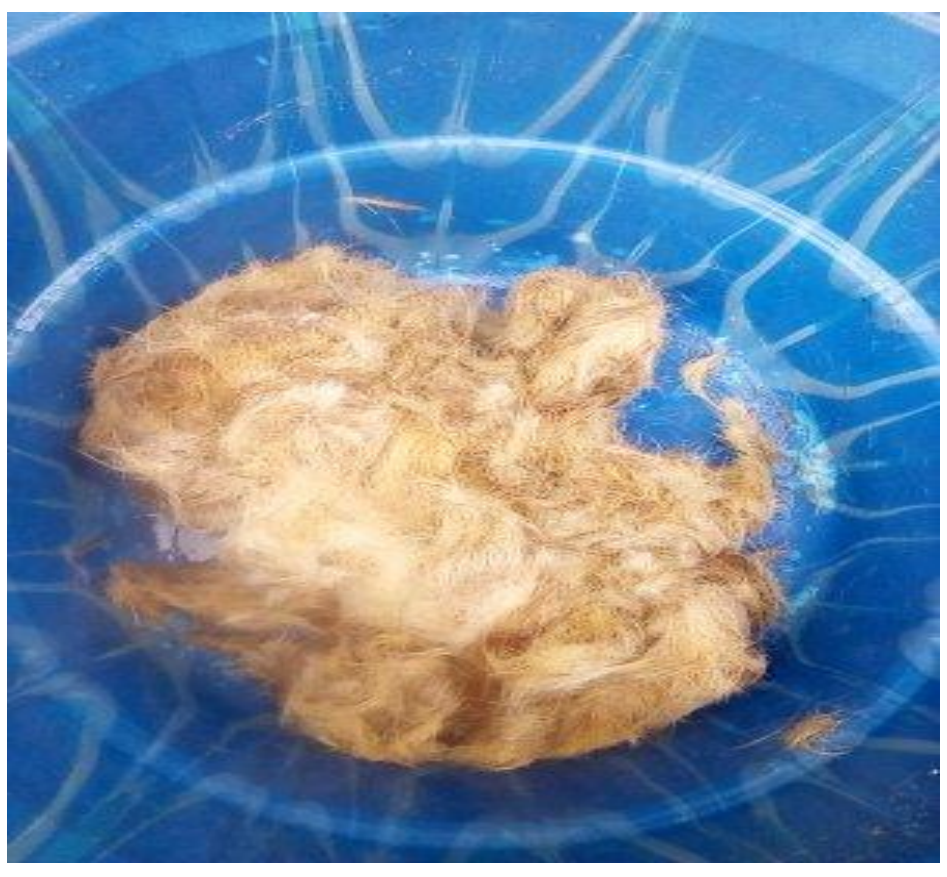

Plate 9: Raw Sheared Sheep Fibres

Plate 9 shows the result of the sheared fibres of the sheep. The sheep fibres are creamy white in colour. It has inherent constituents and acquired impurities such as dried sweat (suint), grease, blood, soil matters, dust, dirt, straw, manure and vegetable matters. 


\subsubsection{Result from Pre-treatment of the Sheep Fibres}

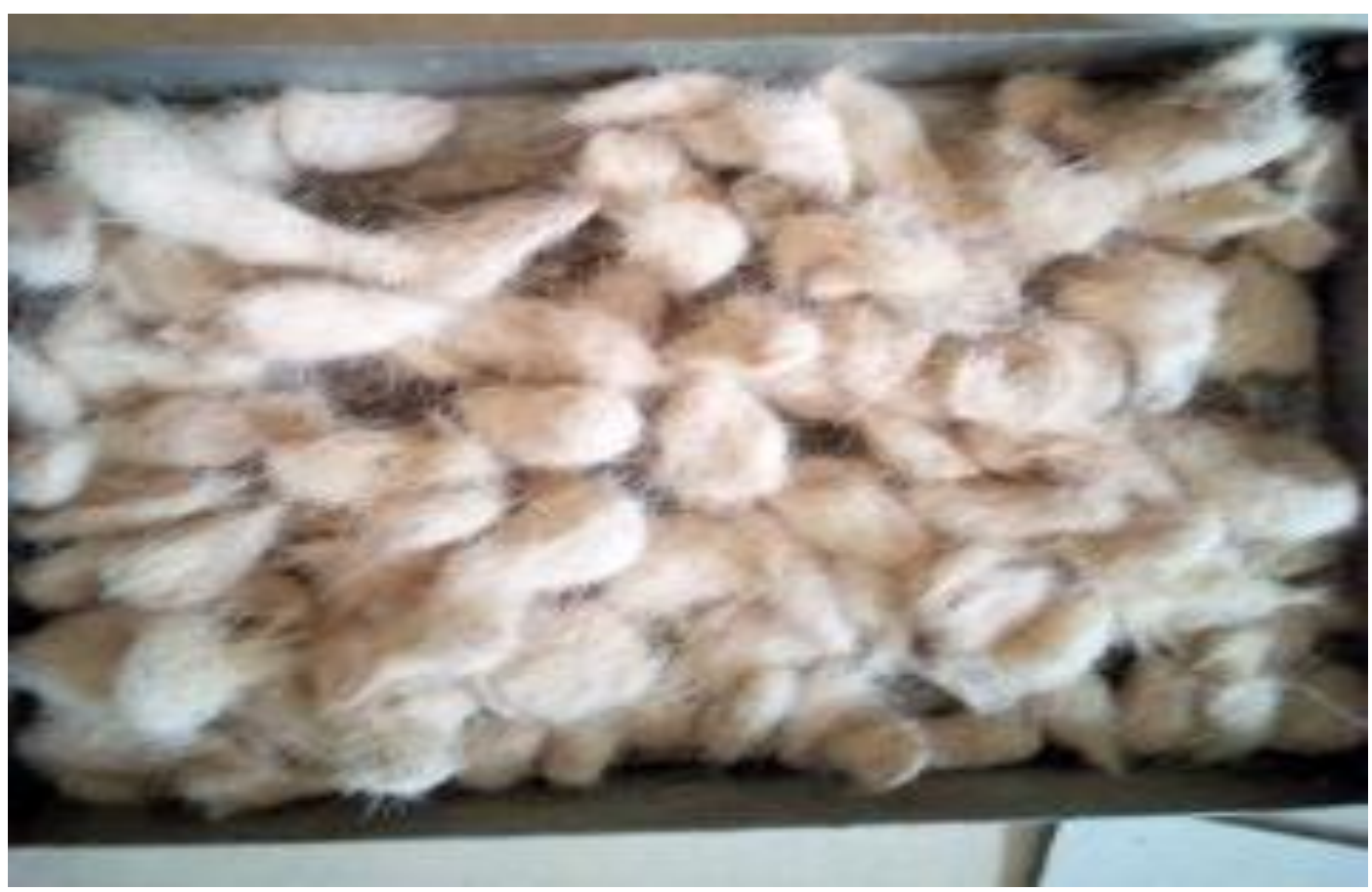

Plate 10: Pre-Treated Sheep Fibres

Plate 10 shows the pre-treated sheep fibres after the removal of the inherent constituents and impurities. The resulting clean fibres are entangled and clustered due to the effect of the pretreatment on it. 


\subsection{Result of the Sheep Fibre Processing}

\subsubsection{Result of fibre separation}

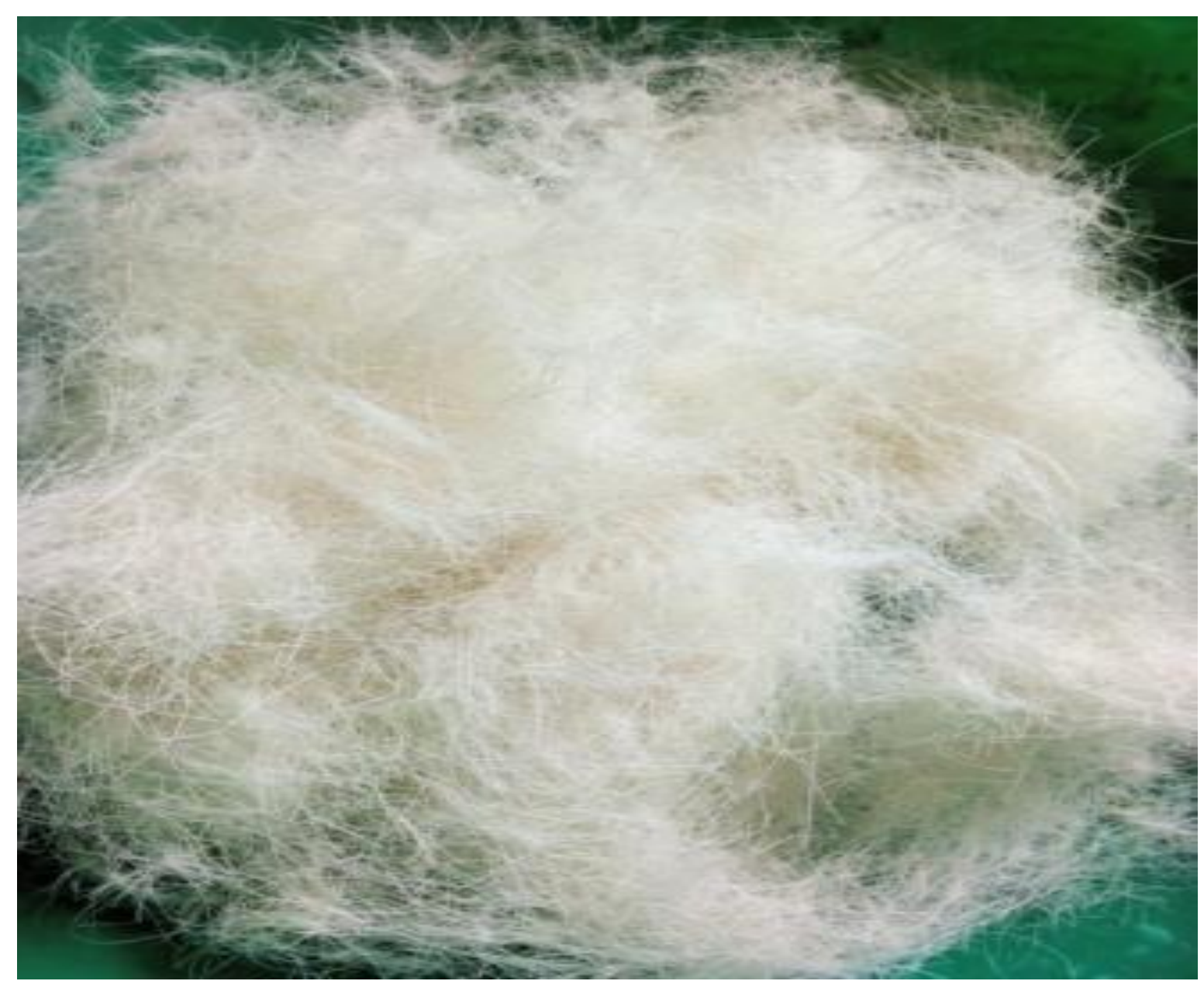

Plate 11: Separated Sheep Fibres

Plate 11 is the separated fibres of the sheep. It can be observed that the fibres are no more clustered like that of the pre-treated. Fibre separations disentangle and singularize the clustered mass of fibres and also further remove hidden impurities that hitherto escape the pretreated stage. It is at this stage that the fibres can be successfully carded. 


\subsubsection{Result of the Sheep fibre Carding}

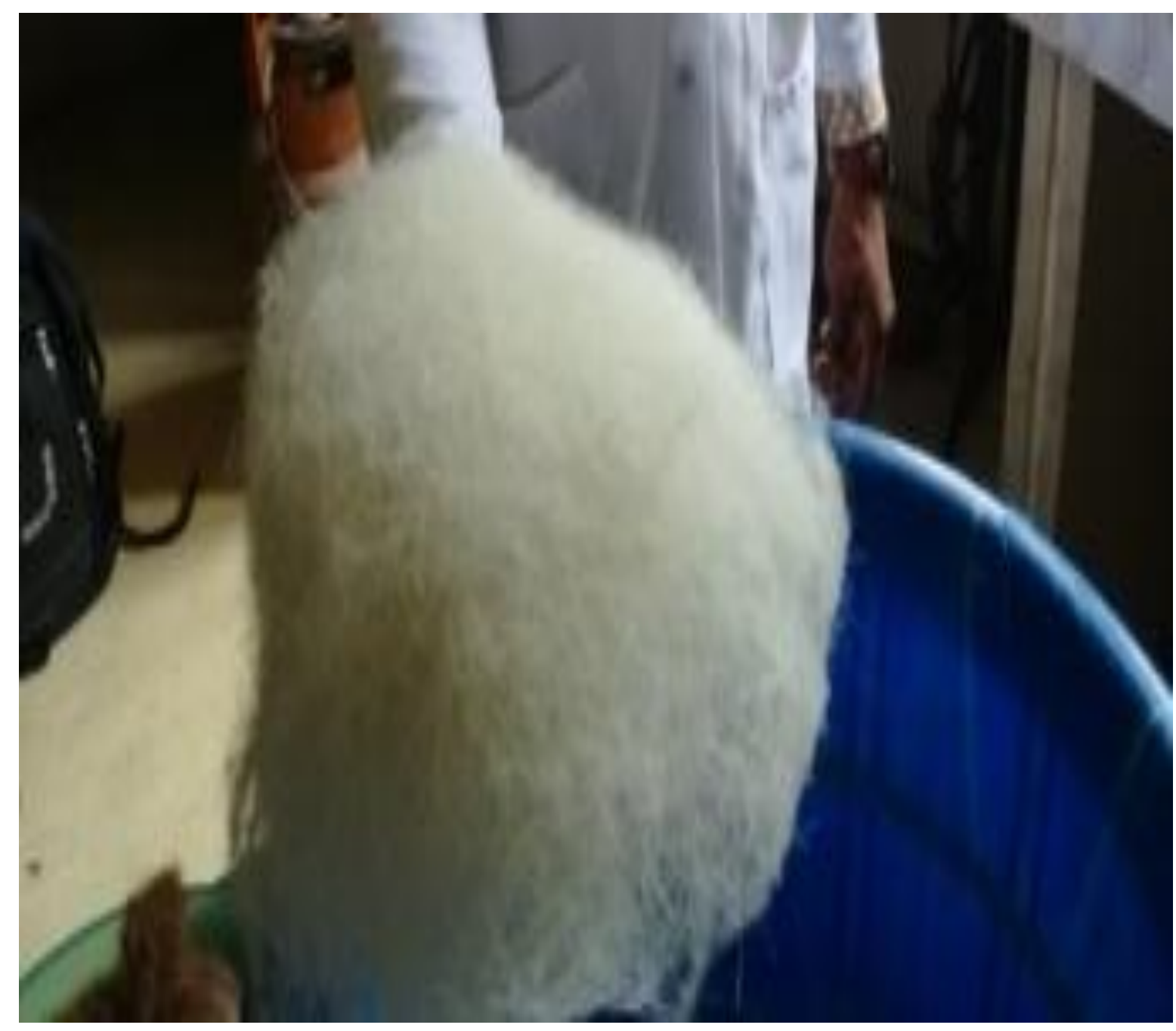

Plate 12: Carded Sheep Fibres

Plate 12 above shows the result of carding the sheep fibres. It gives an evenly thin web of fibres and almost totally eliminate any further impurities. 


\subsection{Result of the Moisture Content and Water Absorption Test}

\subsubsection{Result of the Moisture Content}

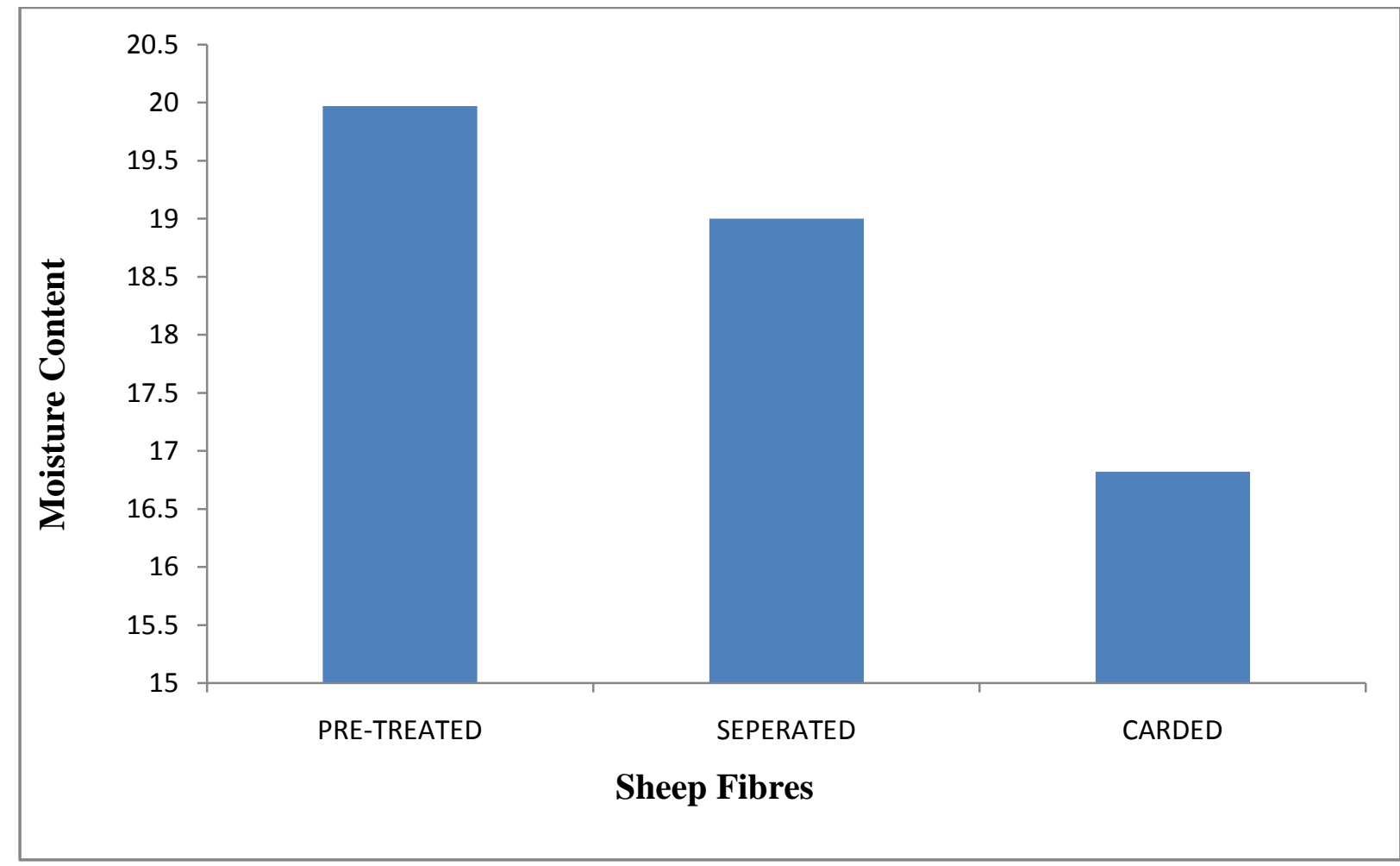

Figure 1: Bar Chart Showing Moisture content of the pre-treated, separated and carded fibres of the Sheep. 


\subsubsection{Result of Water Absorption}

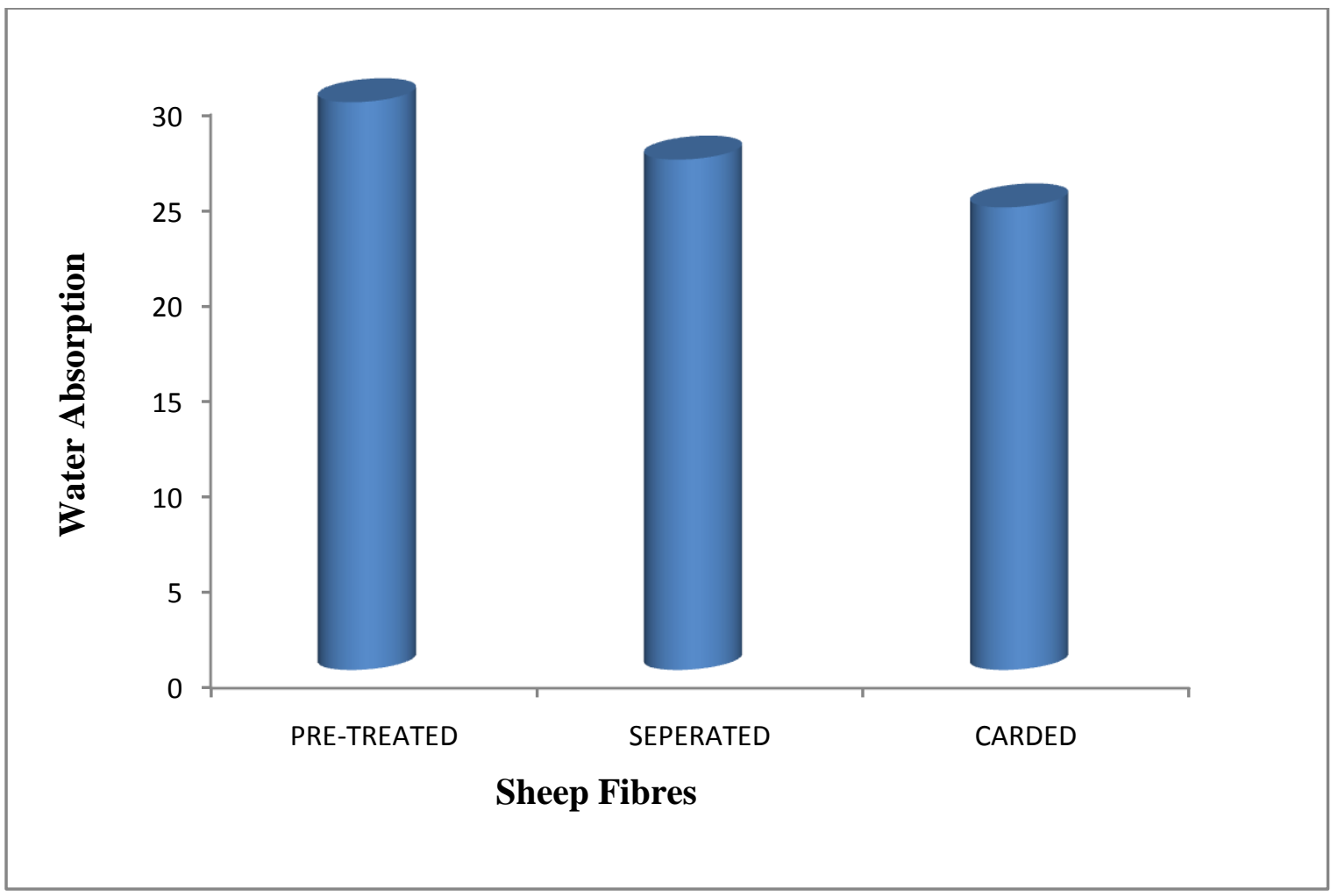

Figure 2: Bar Chart showing the Water Absorption of the Pre-Treated, Separated and Carded Fibres of the Sheep

The sheep fibres have a unique surface structure of overlapping scales called the cuticle cells and therefore can easily absorb and retain moisture due to the pores on its scales in the cuticle layer.

Figures 1 and 2 are the graphs showing the moisture content and water absorption of the pretreated, separated and carded fibres of the sheep.

It can be observed that the pre-treated fibres absorb water and have higher moisture content than the separated and carded fibres. This is because at the pre-treated stage, the cuticle of the fibres has more over lapping scales and therefore its pores easily absorb water and retains moisture.

At the separated stage, the fibre scales are further orientated and aligned which reduce the pore size and therefore reduce the water absorption and retain less moisture.

However, the pore size of the fibres is further reduced by carding and therefore absorbs and retains moisture the least. 


\subsection{CONCLUSION}

The Nigerian sheep fibre undergoes different stages of pre-treatment and processing depending on their end use. This work has shown that these stages affect the rate of water absorption and moisture retention mainly because of the nature of its pore size as a result of their scale structure which is altered by these processes. For this research, separating and carding the sheep fibres not only helps in further removing any escaped impurities from the pre-treatment stage but reduces the rate of water absorption and moisture content. 


\subsection{REFERENCES}

Banerjee, R., Mandal, P.K., Bose, S., Banerjee,M. and Manna, B. (2009).Quality evaluation of meat, skin and wool from garole sheep-a promising breed from India. Asian J. Anim. Sci., 3: 39-46.

Braaten, W. (2005). "Wool". In Steele, Valerie. Encyclopedia of Clothing and Fashion Thomson Gale. pp. 441-443. ISBN 0-684-31394-4.

Cottle, D. J. (1991).The Sheep Industry. Australian Sheep And Wool Handbook, Inkata Press, Melbourne: 3-18.

Glaser, L.K. (1996). Industrial Uses Of Agricultural Materials. Situation And Outlook Report, Commercial Agriculture Division, Economic Research Service, USDA, USA.

Garner, W., 1997. Textile Laboratory Manual: Detergents. 3rd Edn., National Trade Press, London,UK,pp63-66

Hassan, M.M., Leighs, S.J. (2017) Quick-Dryability of Various Quick-Drying Polyester And Wool Fabrics Assessed By a Novel Method. Drying Technol;35:585-592.

Makinson, K. R. (1979). Shrinkproofing of Wool, "Lamellar Subcomponents Of The Cuticular Cell Membrane Complex Of Mammalian Keratin Fibres Show Friction And Hardness Contrast By Afm." Journal Of Microscopy-Oxford 206: 182-193.

Popescu, C. and Wortmann F. J. (2010). Wool - Structure, Mechanical Properties And Technical Products Based On Animal Fibres. IndustrialApplications Of Natural Fibres: Structure, Properties and Technical Applications. J. Mussig. West Sussex, Wiley \& Sons, Ltd: 255-266.

Sawbridge, M. And J. Ford (1987). Textile Fibres Under The Microscope, Shirley Institute Publication, pp.50-53 